\title{
FREQUENCY SELECTIVE CONTROL OF A PARALLEL ACTIVE FILTER WITH RESONANCE FILTER REGULATORS
}

\author{
O. Krievs, L. Ribickis \\ Riga Technical University, \\ 1. Kronvalda Blvd., Riga, LV-1010, LATVIA \\ e-mail: oskars@eef.rtu.lv
}

\begin{abstract}
The paper describes a method for frequency selective control of parallel active filters that are applied for compensation of the current harmonic distortions and the displacement power factor in symmetrical three-phase systems with a known harmonic spectrum. For simulation, an active filter for harmonic current compensation of a three-phase full-bridge diode rectifier was used. Comparative analysis has shown a good agreement between the results obtained experimentally and by simulation
\end{abstract}

\section{INTRODUCTION}

Power electronic converters widely spread in the industrial and household equipment nowadays often draw explicitly non-sinusoidal current from the utility grid, which in some cases can distort the supply voltage waveform. In order to protect the utility grid and to provide safe operation of individual consumers, several standards (such as IEC 555-2, IEEE STD 519, IEC 100-3-2, EN50160, etc.) have been established for the manufacturers of electrical equipment and individual nonlinear consumers in many countries of the world. These standards define limitations to harmonic current drawn from the grid and to its impact on the supply voltage waveform depending on the ratio between the power of a nonlinear consumer and that supplied at the point of common coupling (PCC). Traditionally, passive LC filters have been used to suppress the supply voltage harmonics, being a relatively simple and cost-effective solution. However, passive filters are known to cause unwanted resonances in the utility grid and their performance is dependent on the voltage source impedance at the PCC [1].

The improvement of electrical energy transmission efficiency has also long been realized using passive power factor compensators containing capacitors or inductors. Such approach has turned out to be sufficiently effective, provided that the load can be regarded as a linear circuit drawing sinusoidal current at sinusoidal grid voltage. In the case of nonlinear loads, the application of passive capacitive power factor compensators can be problematic, since their reactance is decreased for higher voltage harmonic components.

As an alternative to passive filters and power factor compensators, active power filters have been widely studied since their basic compensation principle was introduced in 1971 by Sasaki and Machida [2]. Many active filter topologies have been proposed ever since, parallel active filter being one of the most popular 
due to its robustness and good performance. The parallel active power filter is connected in parallel with the nonlinear load and, in fact, acts as a controlled nonsinusoidal current source (Fig. 1a). The power circuit of the filter typically consists of a voltage source inverter with a pulse width modulation (PWM) current control loop and inductor $l_{f}$, which, in combination with a DC-link capacitor $C$, performs the voltage boost operation. The inductor $l_{f}$, also acts as a low-pass filter for the injected current $i_{f, a b c}$ [3]. The filter current $i_{f, a b c}$ is formed so as to obtain sinusoidal supply current $i_{t}$ when summing with load current $i_{s l, a b c}$.

The task of the control system of the parallel active filter is to control the filter current in order to generate the selected compensating current, and to regulate the DC link voltage in order to keep it constant and higher than the amplitude of the network line voltage. The performance of the active filter as a controlled current source greatly depends on the operation speed and precision of the current regulator implemented in the control system.

The development of PWM current regulators for three-phase voltage source inverters is a widely studied topic, since this configuration forms the basis for most of the direct torque control systems of AC drives [4]. However, unlike in the case of current regulators of $\mathrm{AC}$ drives, the shape of the current reference signal in parallel active filters is far from sinusoidal, and it is a complex task to obtain a zero stationary error at comparatively high values of the current increment speed.

\section{SELECTIVE FREQUENCY CONTROL OF THE PARALLEL ACTIVE FILTER CURRENT}

If the harmonic spectrum of the non-linear load current to be compensated is well known, frequency selective control algorithms can be implemented in the control system of a parallel active filter. Such control algorithms are characterised by a modular structure containing several separate current regulators for each harmonic to be compensated. Frequency selective current regulators offer good static and dynamic performance, even though such approach requires more complex control computations [5-10].

The three-phase three-wire circuit of the investigated parallel active filter is demonstrated in Fig. 1. Its general configuration is shown in Fig. 1a, and the control system measuring three-phase load current, three-phase active filter current, line voltages at the PCC and the DC link voltage of the filter - in Fig. $1 b$. The control system consists of two control loops - of DC link voltage and of filter current.

The DC link voltage control loop is comparatively slow. It contains a standard PI regulator, whose input signal is the error of DC link voltage regulation, while its output signal $i_{d, 1}$ is supplied to the filter current reference generator (Fig. 2.), where it contributes to the mean value of filter current $i_{d}$ in the synchronous $d q$ (Park's) reference frame; this latter, in accordance with the so-called $p-q$ instantaneous power theory [11], determines the flow of active power in the system. The task of this control loop is to keep the DC link voltage constant (in an acceptable approximation) and equal to the given reference value compensating active losses of the filter power converter and maintaining a suitable level of the DC voltage. 

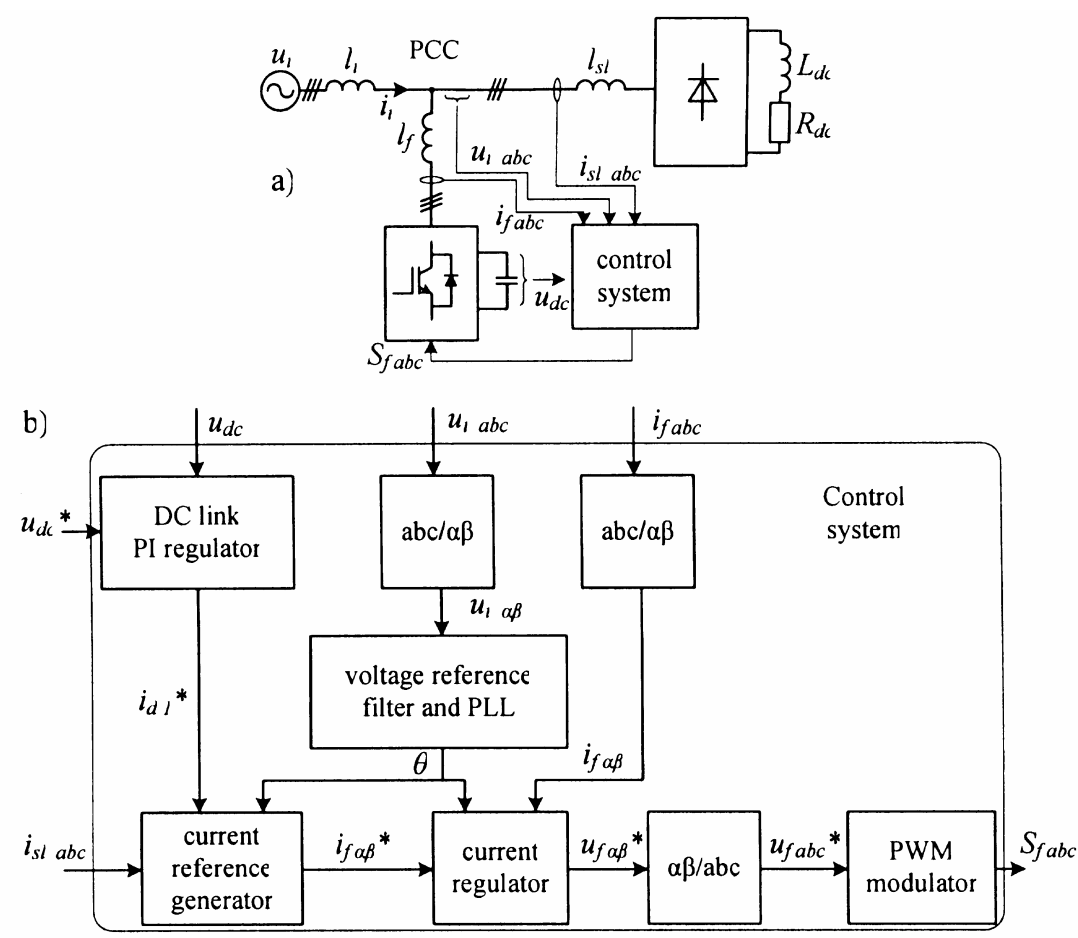

Fig. 1. The parallel active filter system:

a) general configuration, $b$ ) block diagram of the control set.

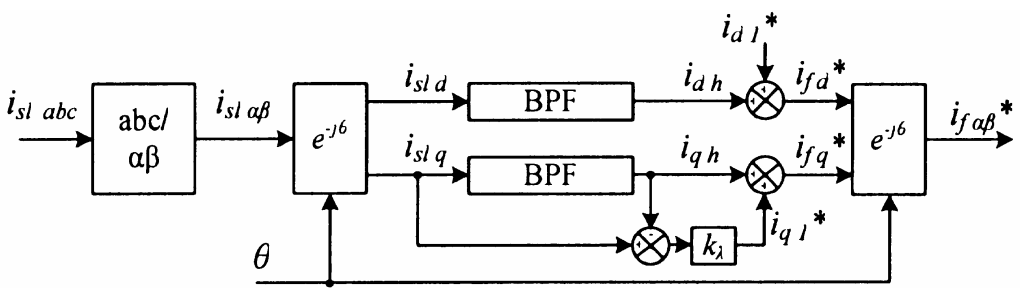

Fig. 2. Block diagram of the current reference generator for the active filter.

The control loop of filter current is a high-speed system containing a novel frequency selective regulator of the filter current with multiple resonance filter regulators (RFR) in the synchronous reference frame.

The reference of the current control loop is a signal that corresponds to the higher harmonic content of the load current to be compensated, containing also the fundamental components for the control of filter's DC voltage and compensation of the displacement power factor of the load, if required. The reference signal is calculated from the load current $i_{s l, a b c}$ measurements, filtering out the high frequency components in the synchronous reference frame, which, according to the $p-q$ theory, corresponds to the separation of higher harmonics of the current. The scheme of current reference extraction is given in Fig. 2.

Current $i_{s l, \alpha \beta}$ in the stationary reference frame is found with the help of Clark's coordinate transformation. The synchronous $d q$ reference frame is obtained applying the coordinate transformation for the current vector given as 


$$
\mathbf{i}_{d q}=\mathbf{D i}_{\alpha \beta},
$$

where $\mathbf{i}_{d q}$ is the current vector in the synchronous reference frame,

$\mathbf{i}_{\alpha \beta}$ is the current vector in the stationary reference frame,

D is a coordinate transformation matrix written as

$\mathbf{D}=\left[\begin{array}{cc}\cos \theta & \sin \theta \\ -\sin \theta & \cos \theta\end{array}\right]$

$\theta \quad$ is the position of the voltage vector at PCC.

To extract the higher harmonics, high-pass filters of the second order are traditionally used instead of band-pass filters shown in Fig. 2. Here band-pass filters of the second order are applied to filter off the high frequency interference the upper cut-off frequency is $5 \mathrm{kHz}$ and the lower one is $20 \mathrm{~Hz}$.

As mentioned before, after the extraction of higher harmonics a regulation of the mean values of the filter's current references along $d$ and $q$ axes is performed: in the $d$-axis - to control the level of the active filter's DC voltage, and in the $q$ axis - to compensate the displacement power factor of the load (if necessary). This latter compensation, however, significally increases the required power rating of active filter. The reference of the filter current is subsequently supplied to the frequency selective filter current regulator with RFRs.

A RFR is a resonance filter of the second order with its transfer function [10] described as

$$
H_{\mathrm{RFR}}(s)=k_{p}+\frac{2 k_{i} \cdot s}{s^{2}+\omega_{0}^{2}} .
$$

The state-space model of transfer functions is:

$$
\left\{\begin{array}{l}
\frac{d}{d t}[x]=[A] \cdot[x]+[B] \cdot u \\
y=[C] \cdot[x]
\end{array}\right.
$$

where $[x]=\left[\begin{array}{l}x_{1} \\ x_{2}\end{array}\right]$ is the vector of states;

$$
[A]=\left[\begin{array}{cc}
0 & \omega_{0} \\
-\omega_{0} & 0
\end{array}\right],[B]=\left[\begin{array}{c}
2 \cdot k_{i} \\
0
\end{array}\right] \text { and }[C]=\left[\begin{array}{ll}
1 & 0
\end{array}\right] \text { is a matrix of the }
$$

coefficients;

$\omega_{0}$ is the resonance frequency;

$u$ is the system's input;

$y$ is the system's output.

Discretization of the given RFR model in Eq. (4) yields:

$$
\left\{\begin{array}{l}
{[x]_{k+1}=[A]_{d} \cdot[x]_{k}+[B]_{d} \cdot u_{k}} \\
y_{k}=x_{1 k}
\end{array}\right.
$$


where $[A]_{d}=\left[\begin{array}{cc}\cos \left(\omega_{0} T_{5}\right) & \sin \left(\omega_{0} T_{5}\right) \\ -\sin \left(\omega_{0} T_{5}\right) & \cos \left(\omega_{0} T_{5}\right)\end{array}\right]$

$$
[B]_{d}=\frac{2 \cdot k_{i}}{\omega_{0}}\left[\begin{array}{c}
\sin \left(\omega_{0} T_{5}\right) \\
\cos \left(\omega_{0} T_{5}\right)
\end{array}\right] \text {; }
$$

$T_{s}$ - discretization time step.

At high values of the RFR resonance frequency, $\omega_{0}$, the delay in the time step of discretization, $T_{s}$ (in the system under investigation this step equals the PWM period, i.e. 100 $\mu$ s) negatively influences the operation of the control system and operational stability of the active filter. According to Eq. (5), the RFR states $x_{1}$ and $x_{2}$ in the stationary mode are sinusoidal and mutually displaced by 90 electric degrees, therefore the mentioned delay can be compensated with the help of the following transformation:

$$
y=[C] \cdot\left[\begin{array}{cc}
\cos \left(\omega_{0} k T_{S}\right) & 0 \\
0 & \sin \left(\omega_{0} k T_{s}\right)
\end{array}\right] \cdot\left[\begin{array}{l}
x_{1} \\
x_{2}
\end{array}\right],
$$

where $k$ is the number of the discretization time steps to be compensated $(k \geq 1)$.

The best results in the simulation and experimental research of the considered system have been obtained at the value $k=2$.

In [5] and [9] a frequency selective current regulator is proposed that applies a separate integrator for each dominant harmonic of the load current. The integrators are implemented in synchronous reference frames rotating at the frequency and in the direction of the corresponding harmonic. In order to avoid the necessity for multiple coordinate transformations of the reference system, the authors of [10] propose to implement several RFRs, each tuned to a particular harmonic to be compensated in a stationary (Clark's) reference frame.

In this paper, a frequency selective current regulator is proposed which consists of one RFR in the stationary reference frame intended for regulation of the fundamental filter current component, and four RFRs tuned to the dominant filter current harmonic components in synchronous reference system aligned with the voltage vector at PCC. Application of RFRs in the frequency selective current regulator has several advantages:

1) RFR provides a zero steady-state error for the sinusoidal input signal (for the selected harmonic) at resonance frequency $\omega_{0}$;

2) since RFR operates as a resonance filter, it is possible to use several parallel RFRs to control several sinusoidal signals of different frequencies;

3) RFR can be applied for the signals of positive and negative sequences.

The load current harmonics to be compensated in the investigated system as well as their order and the phase sequence in the stationary and synchronous reference frames are listed in Table 1.

The advantage of the developed current regulator over the regulators described in [5], $[9,10]$ is the fact that in a synchronous reference frame rotating at the fundamental frequency $\omega_{1}$ one RFR tuned to frequency $6 k \omega_{1}$ makes it possible to control two higher harmonics with frequencies $(6 k \pm 1) \omega_{1}$, which allows the calculations of the control algorithm to be considerably simplified. 
Current harmonics for a three-phase bridge rectifier with inductive load

\begin{tabular}{|c|c|c|}
\hline $\begin{array}{c}\text { Order of the load current } \\
\text { harmonics in Clark's } \\
\text { reference frame }\end{array}$ & $\begin{array}{c}\text { Phase sequence in } \\
\text { respect to the voltage } \\
\text { phase sequence at PCC }\end{array}$ & $\begin{array}{c}\text { Order of the harmonics of load current } \\
\text { and phase sequence in Park's } \\
\text { reference frame }\end{array}$ \\
\hline 1 & Positive & 0 \\
\hline 5 & Negative & 6, Negative \\
\hline 7 & Positive & 6, Positive \\
\hline 11 & Negative & 12, Negative \\
\hline 13 & Positive & 18, Negative \\
\hline 17 & Negative & 18, Positive \\
\hline 19 & Positive & 24, Negative \\
\hline 23 & Negative & 24, Positive \\
\hline 25 & Positive & \\
\hline
\end{tabular}

The block diagram of the proposed frequency selective current regulator is shown in Fig. 3. The control error $\varepsilon_{f, \alpha \beta}$ of filter current $i_{f}$ in the $\alpha \beta$ reference frame is supplied to an RFR with a proportional gain in the stationary reference frame to control the fundamental component of $i_{f}$. In order to control the higher harmonics of the filter current, the control error $\varepsilon_{f, \alpha \beta}$ is transferred into the synchronous reference frame rotating with the frequency of fundamental harmonic $\omega_{1}$, and supplied to four RFRs tuned to the frequencies of the dominant higher harmonics of the non-linear load current in the synchronous reference frame: $\omega_{0}=6 \omega_{1}, 12 \omega_{1}$, $18 \omega_{1}$ and $24 \omega_{1}$ (Table 1). The outputs of these four RFRs are summed and transferred back into the stationary reference frame, and, summing with the output of the fundamental RFR, inverter's voltage reference $u_{f, \alpha \beta} *$ is obtained in the $\alpha \beta$ reference frame. Before being supplied to a PWM modulator which generates control signals for the inverter switches, the voltage reference $u_{f, \alpha \beta} *$ is transformed into a three-phase $a b c$ reference frame using the inverse Clark transformation.

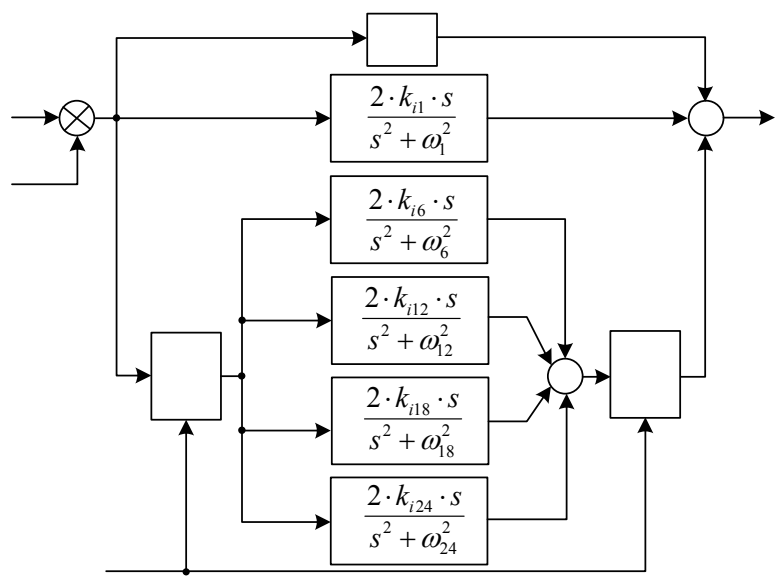

Fig. 3. The designed frequency selective regulator of filter current with RFRs in the synchronous reference frame. 


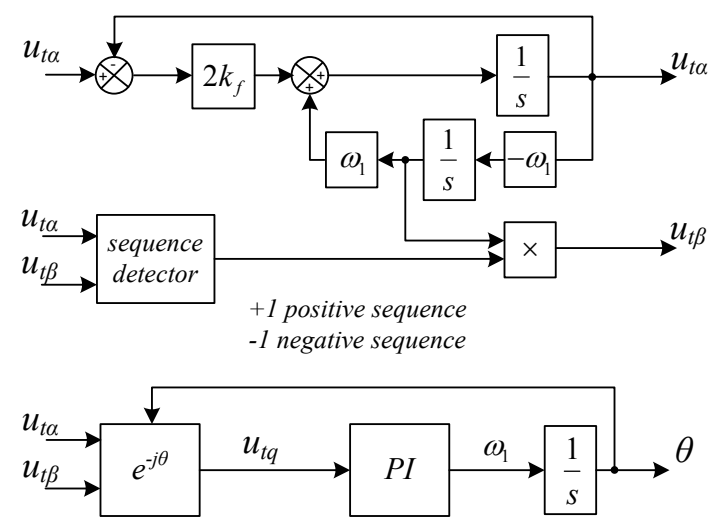

Fig. 4. PLL for finding position $\theta$ of the supply voltage vector with resonance filter.

The voltage vector position at PCC, $\theta$, (needed for computation of all synchronous reference frame transformations implemented in the current control loop) is found from measurements of the line voltages at PCC implementing a phase locked loop (PLL) system shown in Fig. 4. Here again, an RFR for voltage signal filtering in the $\alpha \beta$ reference frame is used to obtain a smooth signal corresponding to the fundamental component of the PCC voltage vector. Inaccuracy in the determination of supply voltage position $\theta$ would negatively influence the operation of the whole control system.

Taking into account that states $x_{1}$ and $x_{2}$ of the RFR regulator in the stationary mode are sinusoidal and mutually shifted by $90^{\circ}$, it is possible to apply a resonance filter only for the $\alpha$-component of the voltage vector, finding the $\beta$ component from the state $x_{2}$ with its sign (which depends on the voltage phase sequence) determined before. The PLL contains a PI regulator which provides that the component of voltage vector $u_{q}$ in the synchronous $d q$ reference frame is zero in the stationary mode, thus precisely defining the position of the voltage vector.

\section{SIMULATION AND EXPERIMENTAL RESULTS}

In order to investigate the developed control method, a computer model of the parallel active filter system in MATLAB/SIMULINK environment has been elaborated. The control algorithm is realized with the help of $\mathrm{C}$ language system function. The use of $\mathrm{C}$ language algorithm in SIMULINK environment allows applying the same control code for simulation in MATLAB/SIMULINK environment as well as for experimental investigations using the Dspace ${ }^{\circledR}$ platform; being transferred to a fixed point format, it could be applied for the industrial parallel active filter control with a DSP processor.

The control system's operation in the whole simulation time $(t=0-0,6 \mathrm{~s})$ is shown in Fig. 5. At $t_{1}=50 \mathrm{~ms}$ a soft-start loading resistance of the active filter capacitor is by-passed. At $t_{2}=80 \mathrm{~ms}$ the execution of the control algorithm starts the phase sequence of supply voltage is detected and, after eight mains cycles, the PLL starts its operation. The time delay is needed for the PLL to start the operation at fully stabilized supply current and voltage using the same control algorithm in 
the experimental prototype. After three more mains cycles $\left(600 \cdot T_{s}=60 \mathrm{~ms} ; T_{s}=\right.$ $=100 \mu \mathrm{s})$ the PLL operation is stabilized and the PWM control loading the capacitor up to its reference voltage $\left(u_{d c}{ }^{*}=730 \mathrm{~V}\right)$ is actuated. At $t_{3}=400 \mathrm{~ms}$ the compensation of the current harmonic distortion is started.
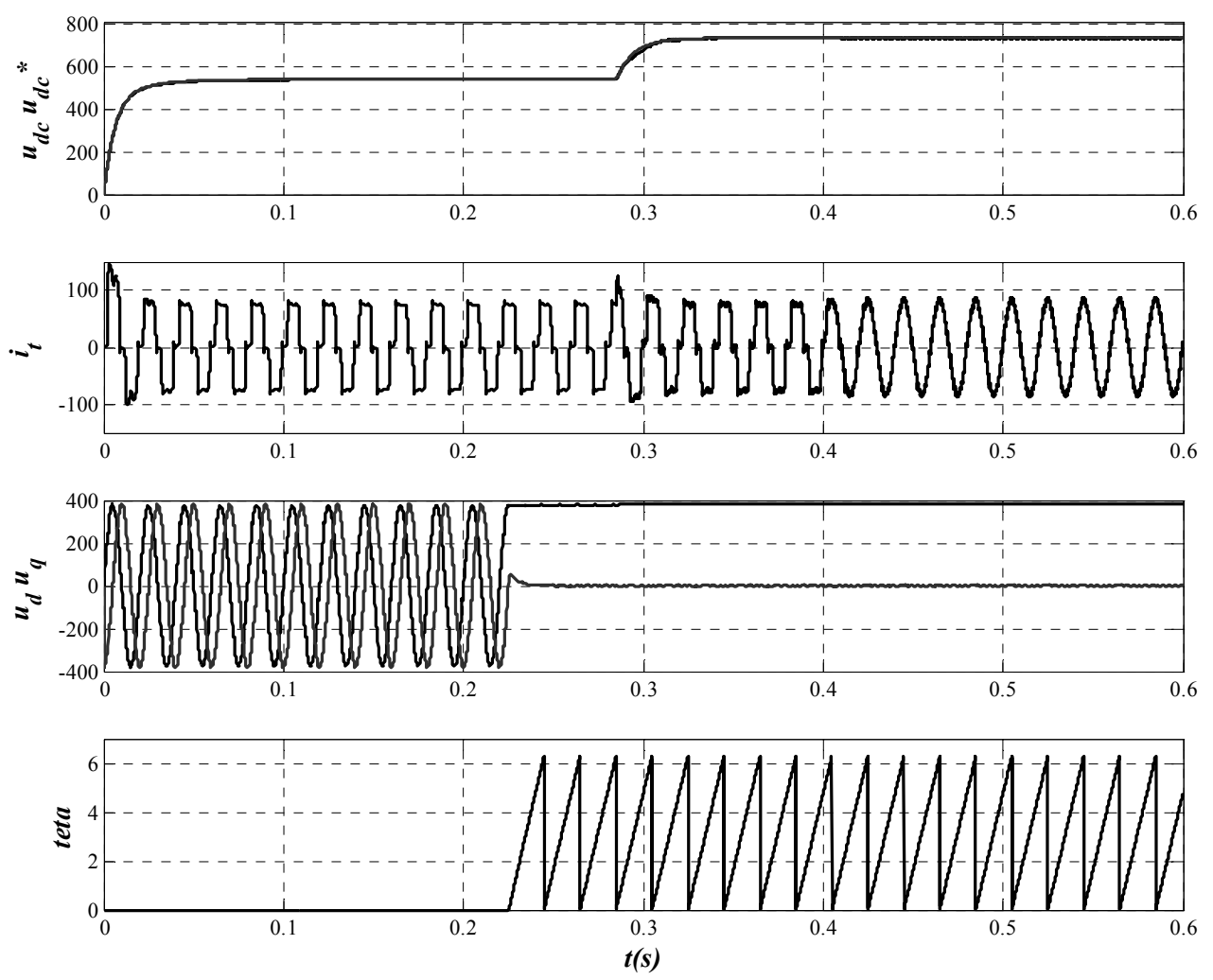

Fig. 5. Operation of the control system during the whole simulation time: the reference $u_{d c}{ }^{*}$ and actual $u_{d c}$ values of DC link voltage; supply current of one phase $i_{t}$, components $u_{d}$ and $u_{q}$ of the supply voltage vector in the synchronous reference frame and its phase relative to the stationary reference frame teta.

The PLL with RFR performs the filtering function rejecting disturbances in the supply voltage. It should be mentioned that in the model of the supply voltage the 5 -th $(2 \%)$ and the 7 -th $(1.1 \%)$ harmonics are introduced.

The current regulator operation in a stationary mode is demonstrated in Fig. 6. From the simulation results it is obvious that the developed regulator follows well the reference signal - the highest regulating error appears at a high reference signal increment that corresponds to higher compensated harmonics, where the time delay caused by the discretization time step has a greater negative influence.

The simulated currents of the active filter system for one phase in the stationary mode are illustrated in Fig. 7. The figure shows that the harmonic distortion of the load current is well compensated by the active filter - it is evident also from the total harmonic distortion (THD) factor of the supply current calculated from the simulation results $(\mathrm{THD}=2.5 \%)$. 

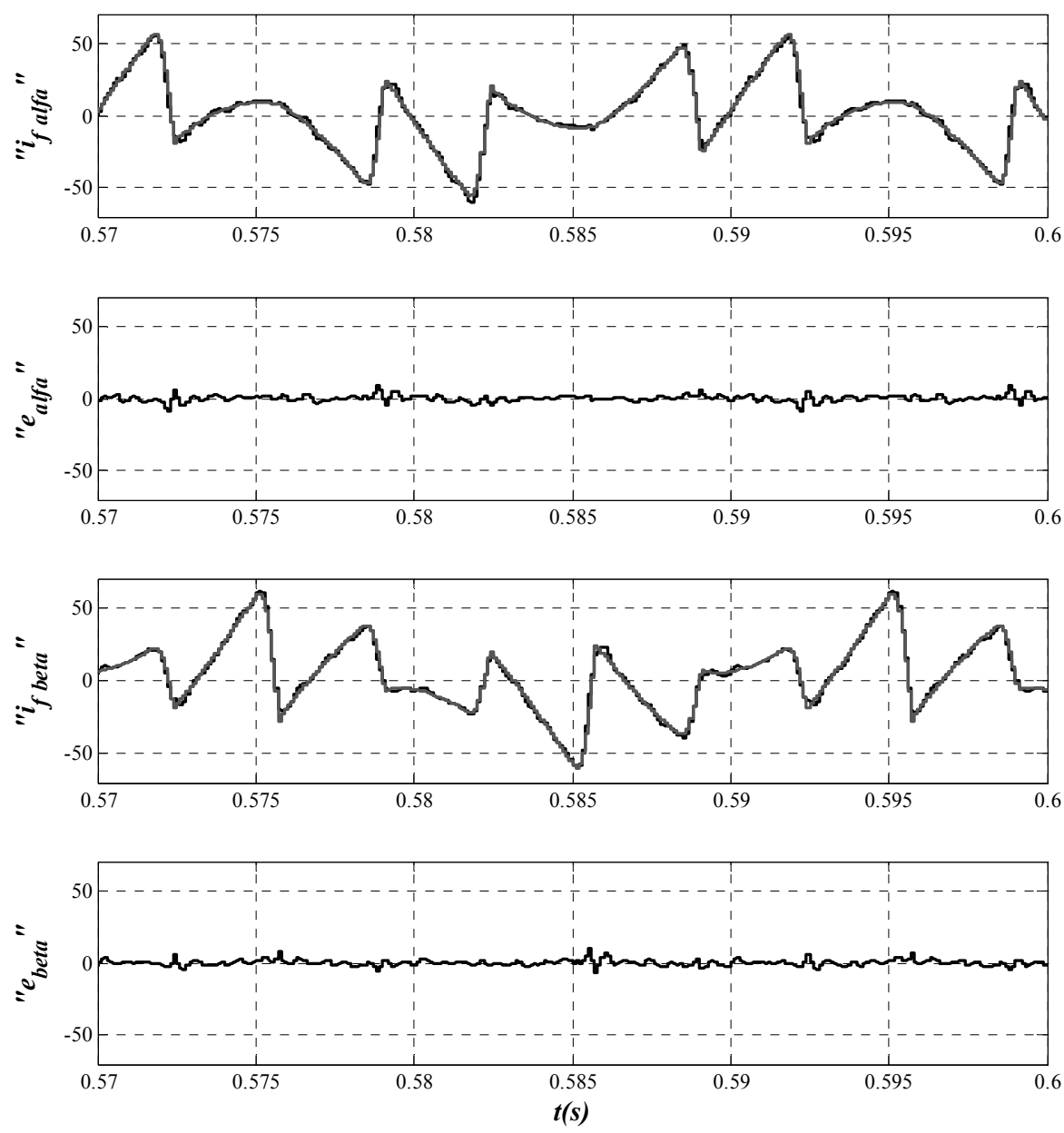

Fig. 6. Operation of the developed current regulator in the steady-state mode: current reference $i_{f a l f a_{*}{ }^{*}}$ and actual $i_{\text {falfa }}$ values, control error $e_{\text {alfa }}(\alpha$-axis); current reference $i_{\text {fbeta }}$, and actual $i_{\text {fbeta }}$ values, control error $e_{\text {beta }}(\beta$-axis).
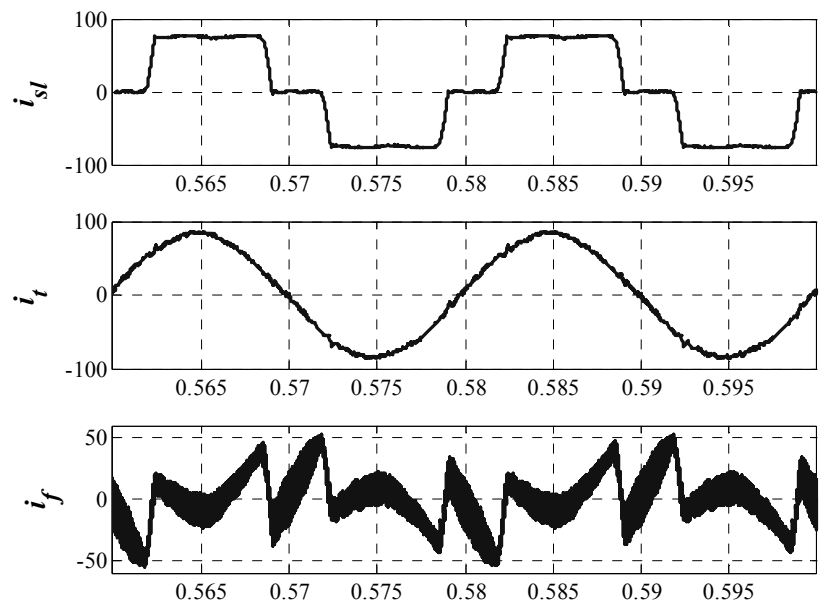

$t(s)$

Fig. 7. Currents of the parallel active filter for one phase in steady-state mode: load current $i_{s l}$, supply current $i_{t}$, and filter current $i_{f}$. 
To evaluate the performance of the developed frequency selective current regulator, experiments have been carried out using a $30 \mathrm{kVA}$ three-phase three-wire parallel active power filter system prototype located at Turin Technical University. In the control system's setup a Dspace ${ }^{\circledR}$ prototyping platform was applied, which allowed real time investigation of the control algorithms to be realized in MATLAB/SIMULINK environment. The parallel active filter setup applied in the experiments corresponds to the block diagram in Fig. $1 a$.

The main parameters of the experimental setup are summed up in Table 2.

Parameters of the modified experimental prototype of the active filter system

\begin{tabular}{|l|c|}
\hline The RMS value of the line voltage, $\mathrm{V}$ & 380 \\
\hline The RMS value of the phase load current, $\mathrm{A}$ & 62 \\
\hline DC link voltage of the active filter, $\mathrm{V}$ & 730 \\
\hline Inductance of the input inductor of the active filter, $\mu \mathrm{H}$ & 220 \\
\hline Inductance of the input inductor of the rectifier, $\mu \mathrm{H}$ & 280 \\
\hline Inductance of the output inductor of the rectifier, $\mathrm{mH}$ & 15 \\
\hline Switching frequency of the inverter, $\mathrm{kHz}$ & 10 \\
\hline
\end{tabular}

The experimental one-phase current waveforms of the parallel active filter system in the stationary mode with the developed control method are demonstrated in Fig. 8. It is evident that the control algorithm can provide an effective compensation of the harmonic distortion of the load current $\left(\mathrm{THD}_{\mathrm{i}}=2.7 \%\right)$. The experimental results obtained for the parallel active filter system are in a good agreement with the simulation results, which lends credence to the quality of the proposed computer model of the system. The diagrams of currents and THD factors obtained by simulation and in experiments coincide within the error range of $3-4 \%$.

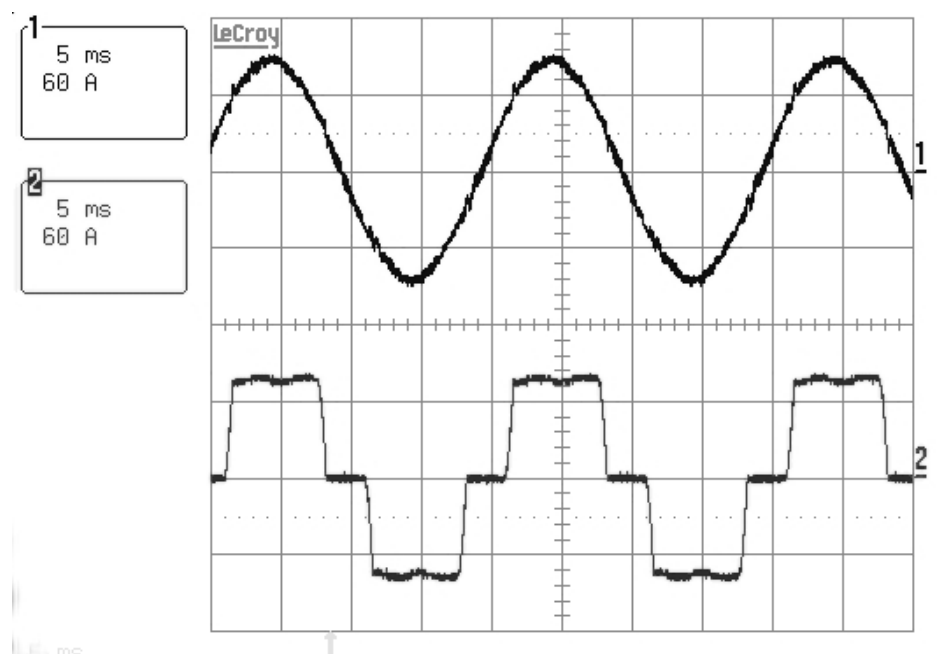

Fig. 8. Supply and load currents of phase A. 


\section{CONCLUSIONS}

A novel method for frequency selective control of a parallel active filter has been developed and tested. The performance of the control method was verified by computer simulation in MATLAB/SIMULINK environment and by experiments using a $30 \mathrm{kVA}$ laboratory prototype of the parallel active filter. The estimated total harmonic distortion factor of the supply current is $\sim 2.6 \%$, which meets the requirements of the IEEE STD 519 standard for high-power equipment that regulates the THD factor of the consumed current (THD $\leq 5 \%$ ). As a result of active filtering, the harmonic distortion factor of the supply current was reduced more than 10 times as compared with that of the non-linear load current without filtering (THD $\approx 27 \%$ ).

An essential advantage of the developed approach is a reduced complexity of the control algorithm, which is of high importance for the industrial production of parallel active filter control systems since it allows the microprocessor resources to be freed for other tasks.

The high quality of the elaborated computer model of the parallel active filter system has been proved by close correspondence of the simulation and experimental results. The obtained diagrams and supply current THD coincide within the discrepancy limits of 3-4\%.

\section{REFERENCES}

1. Bhattacharya, S., Divan, D.M., \& Banerjee, B. (1995). Active Filter Solutions for Utility Interface. Conf. Rec. IEEE ISIE. pp. 53-63.

2. Sasaki, H., \& Machida, T. (1971). A new method to eliminate AC harmonic currents by magnetic compensation - considerations on basic design. IEEE Trans. on PAS, 90 (5), 2009-2011.

3. Krievs, O., Galkin, I., \& Riberio, R.L.A. (2003). Design Considerations for the Power Circuit of a Shunt Active Power Filter. Proceedings of RTU Sci. Conf. Ser. 4. Vol. 10. p. 52 .

4. Kazmierkowski, M.P., \& Malesani, L. (1998). Current Control Techniques for ThreePhase Voltage-Source PWM Converters: a Survey. IEEE Trans. on Industrial Electronics, 45 (5), 691-703.

5. Bojrup, M., Karlsson, P., Alakula, M., \& Gertmar, L. (1999). A multiple rotating integrator controller for active filters. Conf. Rec. EPE, CDROM.

6. Gonzalo, G., Salvia, A., Briozzo, C., \& Watanabe, E. H. (2002.) Control Strategy of Selective Harmonic Current Shunt Active Filter. IEEE Proceedings of Generation Transmission and Distribution. 149 (2), 689-694.

7. Gonzalo, G., Salvia, A., Briozzo, C., \& Watanabe, E. H. (2004). Selective Filter with Optimum Remote Harmonic Distortion Control. IEEE Transactions on Power Delivery, 19 (4), 1990-1997.

8. Matavelli, P. (2001). A Closed-Loop Selective Harmonic Compensation for Active Filters. IEEE Transactions on Industrial Applications, 37 (1), 81-89.

9. Sonnenschein, M., Weinhold, M., \& Zurowski, R. (1996). Shunt-Connected Power Conditioner for Improvement of Power Quality in Distribution Networks. Conf. Rec., 7th International Conference on Harmonics and Quality of Power. 27-32.

10. Yuan, X., Merk, W., Stemmler, H., \& Allmeling, J. (2002). Stationary-Frame Generalized Integrators for Current Control of Active Power Filters with Zero Steady-State 
Error for Current Harmonics of Concern under Unbalanced and Distorted Operating Conditions. IEEE Trans. on Industry Applications. 38 (2), 523-532.

11. Akagi H., Watanabe E.H., \& Aredes M. (2007). Instantaneous Power Theory and Applications to Power Conditioning. New Jersey (USA): John Wiley \& Sons, 379 p.

\title{
PARALĒLĀ AKTĪVĀ FILTRA FREKVENCES SELEKTĪVĀ VADĪBA AR REZONANSES FILTRU REGULATORIEM
}

\author{
O. Krievs, L. Ribickis
}

$$
\text { Kopsavilkums }
$$

Rakstā ir piedāvāta frekvences selektīva vadības metode paralēlā aktīvā filtra pielietošanai simetrisku trīsfāžu sistēmu strāvas harmonisko kropļojumu un reaktīvās jaudas kompensēšanai ar zināmu strāvas augstāko harmonisko komponenšu sadalījumu. Doti izstrādātās vadības metodes datormodelēšanas un eksperimentālo pētījumu rezultāti, aktīvajam filtram kompensējot trīsfāžu tilta nevadāmā taisngrieža ieejas strāvas augstākās harmoniskās komponentes.

08.02.2009. 